This item was submitted to Loughborough's Research Repository by the author.

Items in Figshare are protected by copyright, with all rights reserved, unless otherwise indicated.

\title{
Quantification of landslide velocity from active waveguide generated acoustic emission
}

\section{PLEASE CITE THE PUBLISHED VERSION}

http://dx.doi.org/10.1139/cgj-2014-0226

\section{PUBLISHER}

NRC Research Press (@ the authors)

\section{VERSION}

AM (Accepted Manuscript)

\section{PUBLISHER STATEMENT}

This work is made available according to the conditions of the Creative Commons Attribution-NonCommercialNoDerivatives 4.0 International (CC BY-NC-ND 4.0) licence. Full details of this licence are available at: https://creativecommons.org/licenses/by-nc-nd/4.0/

\section{LICENCE}

CC BY-NC-ND 4.0

\section{REPOSITORY RECORD}

Smith, Alister, and Neil Dixon. 2014. "Quantification of Landslide Velocity from Active Waveguide Generated Acoustic Emission". Loughborough University. https://hdl.handle.net/2134/16091. 
Smith A \& Dixon N (2014) Quantification of landslide velocity from active waveguide-generated acoustic emission. Canadian Geotechnical Journal, 10.1139/cgi-2014-0226

\title{
Quantification of landslide velocity from active waveguide-generated
} acoustic emission

\author{
Alister Smith $^{[1]^{*}}$ and Neil Dixon ${ }^{[1]+}$ \\ ${ }^{[1]}$ School of Civil and Building Engineering, Loughborough University, Leicestershire, UK
}

*Corresponding author. Email: A.Smith10@lboro.ac.uk 


\begin{abstract}
Acoustic emission (AE) has become an established approach to monitor stability of soil slopes. However, the challenge has been to develop strategies to interpret and quantify deformation behaviour from the measured AE. AE monitoring of soil slopes commonly utilises an active waveguide which is installed in a borehole through the slope and comprises a metal waveguide rod or tube with a granular backfill surround. When the host slope deforms, the column of granular backfill also deforms and this generates $\mathrm{AE}$ that can propagate along the waveguide. Presented in the paper are results from the commissioning of dynamic shear apparatus used to subject full scale active waveguide models to simulated slope movements. The results confirm that AE rates generated are proportional to the rate of deformation, and the coefficient of proportionality that defines the relationship has been quantified (e.g. $4.4 \times 10^{5}$ for the angular gravel examined). The authors demonstrate that slope velocities can be quantified continuously in real-time through monitoring active waveguide generated AE during a slope failure simulation. The results show that the technique can quantify landslide velocity to better than an order of magnitude (i.e. consistent with standard landslide movement classification) and can therefore be used to provide an early warning of slope instability through detecting and quantifying accelerations of slope movement.
\end{abstract}

Keywords: Acoustic Emission (AE), Deformation, Instrumentation, Landslide, Slope Instability 


\section{Introduction}

Landslides cause many thousands of fatalities each year all over the globe (e.g. Petley (2012) reported records of over 32,000 fatalities that resulted from landslides during the period 2004 to 2010) and damage built environment infrastructure costing billions of pounds to repair, resulting in thousands of people being made homeless and the breakdown of basic services such as water supply and transport. There is an ongoing need to develop new techniques that can provide early warnings of slope instability to lessen damage and loss of life. It is important that early warning systems used to detect catastrophic first-time failures are sensitive and can detect accelerations of movement as early as possible. The time lag between the onset of failure being detected and communicated to full failure taking place needs to be as great as possible in order to enable evacuation of vulnerable people and timely repair and maintenance of critical infrastructure.

The four stages of soil slope movement defined by Leroueil (2001) are depicted in Figure 1: prefailure; onset of failure; post-failure; and reactivation. It can be seen that the displacement rate (or velocity) vs. time relationship for both first-time failures and reactivations are expected to increase exponentially with time until a peak velocity is reached, and then subsequently decay exponentially until movement ceases and equilibrium is regained. In reactivated landslides formed in fine grained soils the shear surface is already at or close to residual strength and therefore no further strain softening (i.e. brittle loss of strength) can take place and small low velocity movements generally occur (Hutchinson 1988; Leroueil 2001). During first-time failure the velocity of the sliding mass is expected to progress over several orders of magnitude; from the gradual development of a defined failure surface producing low velocities, to the subsequent strength loss during brittle failure generating high velocities. The order of magnitude slope displacement rate classifications initially developed in Schuster \& Krizek (1978) and later modified by Cruden \& Varnes (1996), and extended by Anderson \& Holcombe (2013, p92) are shown in Figure 2. The velocity scale varies over several orders of magnitude, from millimetres per year to metres per second. 
Current methods for monitoring slope displacements can be separated into two categories; surface and subsurface techniques. Surface deformation monitoring methods investigate the change in shape of the ground surface and can provide measurements of the direction and rate of slope movement. Examples of such surface monitoring methods include: photogrammetry (aerial and terrestrial); remote sensing (e.g. InSAR and LiDAR); and surveys of pegs using Total Stations or GPS. Each of these techniques provides high spatial resolution but often low temporal resolution due to the time and cost required to conduct each survey and process the data. Each technique also provides varying levels of accuracy. Subsurface measurements are known to provide accurate and reliable information and inclinometer casings are routinely installed in slopes where it is anticipated shear surfaces exist or could form. In the large majority of applications these casings are read periodically during scheduled site visits (i.e. typically a few times a year) and hence only provide information on historical slope movements (i.e. that have occurred since the last reading). This mode of operation cannot provide continuous measurements or real-time information for use in an early warning system. An option is to install in-place inclinometers for continuous measurement of ground deformations, and these can be linked to communication systems to provide warnings when threshold values are exceeded. ShapeAccelArray (SAA) systems are also available to provide this type of information. However, these in-place continuous deformation measurement systems are relatively high cost to purchase and operate, and this means that their use is currently limited (i.e. only a small percentage of subsurface deformation measurement systems provide continuous measurements and real-time information).

There is a clear need for affordable instrumentation that can provide continuous, remote, real-time information with high temporal resolution on slope movements for use in the protection of people and infrastructure by practitioners and operators. Current systems are either too expensive for wide-scale use or have technical limitations. An approach, Assessment of Landslides using Acoustic Real-time Monitoring Systems (ALARMS) based on detecting and quantifying acoustic emission (AE) generated by an active waveguide (i.e. a steel waveguide situated inside a preformed borehole with a granular backfill surround) installed through a deforming soil slope has been developed and trialled using unitary battery operated sensors (a schematic of the monitoring system can be seen in Figure 3). 
The continuous real-time AE rate monitoring Slope ALARMS sensors (Dixon \& Spriggs 2011) are being used in a number of proof-of concept field trials in the UK (e.g. Dixon et al. 2014a and Dixon et al. 2014b), Italy (e.g. Dixon et al. 2012b), Austria and Canada (e.g. Smith et al. 2014) to monitor AE generated by active waveguides installed through landslides, in order to assess performance in the field environment and to compare against other deformation monitoring instrumentation (e.g. inclinometers and ShapeAccelArray (SAA)). The current sensor comprises a piezoelectric transducer with a $30 \mathrm{kHz}$ resonant frequency and a band pass filter to focus AE detection in the frequency range $20 \mathrm{kHz}$ to $30 \mathrm{kHz}$. This eliminates low frequency environmental noise such as generated by wind, traffic, humans and construction activities, while retaining soil generated AE which falls inside the 20 $\mathrm{kHz}$ to $30 \mathrm{kHz}$ detection range. The sensor also comprises amplifiers, data storage and a power supply. The sensor records ring-down counts (RDC) (e.g. Figure 4) which are the number of times the signal amplitude crosses a programmable voltage threshold level within a predetermined time period (i.e. RDC rates). The units of AE used in this study are ring-down counts (RDC); AE rates have units RDC per hour (RDC/hour).

Koerner et al. (1981) defined the following qualitative AE guide for slope stability assessment:

- Little or no AE; probably not deforming and therefore stable.

- Moderate levels of AE; deforming slightly but marginally stable. Continued monitoring is necessary.

- High levels of $\mathrm{AE}$; experiencing substantial deformations and considered unstable with immediate remedial measures required.

- Very high levels of AE; undergoing large deformations and probably in a state of failure.

Such a classification cannot be used to provide a quantitative assessment on slope stability. Dixon \& Spriggs (2007) found that by applying displacement rates that were separated by orders of magnitude, as commonly used in practice (Figure 2), to active waveguide models with gravel backfill in constant strain rate compression tests, the magnitude of $\mathrm{AE}$ rates generated were also separated by orders of magnitude and proportional to the displacement rate applied. This research demonstrated for the first 
time that $\mathrm{AE}$ monitoring can be used to provide a quantification of slope movement rates. The purpose of the study reported in the present paper was to establish a method that can be used to quantify rates of slope movement from measured $\mathrm{AE}$ rates, continuously and in real-time.

\section{Acoustic emission monitoring of soil slopes using active waveguides}

In soil $\mathrm{AE}$ is generated by inter-particle friction, and hence the detection of $\mathrm{AE}$ is an indication of deformation. The dominant mechanisms for $\mathrm{AE}$ generation within soil are particle-particle interactions such as sliding and rolling friction, and particle contact network rearrangement (e.g. release of contact stress and stress redistribution as interlock is overcome and regained). Other soil generated AE mechanisms include: breakage of adhesive bonds between particles, degradation at particle asperities where contact stresses are very high, and capillary bridge ruptures (Lord \& Koerner 1974; Michlmayr et al. 2012a; Michlmayr et al. 2012b; Michlmayr et al. 2013). Research contributions in understanding the fundamental $\mathrm{AE}$ behaviour of soil have demonstrated that: deforming soil produces detectable $\mathrm{AE}$; the characteristics of $\mathrm{AE}$ generated are governed by the properties of the soil (e.g. AE from fine grained soils are highly influenced by moisture content and plasticity, and $\mathrm{AE}$ events with greatest magnitude are produced in granular soil with large angular particles); and the magnitude of $\mathrm{AE}$ generated is directly related to the stress state of the soil (e.g. $\mathrm{AE}$ events with greater magnitude are generated by deforming soil with high inter-particle contact stresses) (Koerner et al. 1981; Mitchel \& Romeril 1984; Garga \& Chichibu 1990; Shiotani \& Ohtsu 1999; Michlmayr et al. 2013). Properties that influence the AE response of soils are summarised in Table 1.

Various authors have used AE monitoring to assess the stability of both natural and engineered slopes (e.g. Beard 1961; Cadman \& Goodman 1967; Chichibu et al. 1989; Naemura et al. 1990; Nakajima et al. 1991; Rouse et al. 1991; Fujiwara et al. 1999; Dixon et al. 2003). However, as discussed above, interpretation of $\mathrm{AE}$ data has previously been only qualitative until Dixon et al. (2003), Dixon \& Spriggs (2007) and Dixon et al. (2014a) reported research to develop a quantitative 
solution to this problem using AE monitoring of active waveguides. Figure 3 shows a schematic of an active waveguide installed in a deforming slope with a Slope ALARMS sensor coupled to the waveguide at the ground surface. Fine grained soils generate relatively low energy AE signals when deformed and these attenuate significantly over short distances; this necessitates the introduction of sources of increased AE activity. The active waveguide is installed in a borehole that penetrates stable stratum below any shear surface or potential shear surface that may form beneath the slope, and comprises a metal waveguide rod or tube that provides a low attenuation pathway for AE signals to travel from the source to the sensor at the ground surface. The annulus surrounding the waveguide is backfilled with granular soil. When the host soil slope deforms, the column of granular soil also deforms and this induces relatively high levels of $\mathrm{AE}$ that can propagate along the waveguide. The $\mathrm{AE}$ produced from this system does not relate directly to the stress state of the host soil slope in which the active waveguide is installed, however, through calibration of the system it is possible to relate $\mathrm{AE}$ behaviour of the backfill soil column with deformations of the in situ surrounding ground. AE generated in the active waveguide system is induced by a variety of mechanisms: straining of the metal waveguide directly (i.e. in bending); shearing at the interface between the backfill and the waveguide; and compression and shear within the backfill material (i.e. inter-particle friction).

Dixon et al. (2014a) introduced the coefficient of proportionality $\left(\mathrm{C}_{\mathrm{p}}\right)$ as a method to quantify slope displacement rates from measured AE rates, as detailed in Equation 1.

$$
\begin{aligned}
& \mathrm{AE}_{\text {rate }} \propto \text { Velocity } \\
& \therefore \mathrm{AE}_{\text {rate }}=\mathrm{C}_{\mathrm{p}} \mathrm{x} \text { Velocity } \\
& \text { where } \mathrm{C}_{\mathrm{p}}=f \text { (variables) }
\end{aligned}
$$


An increasing rate of deformation (i.e. in response to increasing slope velocity) within the active waveguide generates an increasing number of particle-particle/particle-waveguide interactions (as described earlier in this section) per unit time. Each of these interactions generates a transient $\mathrm{AE}$ event. These transient $\mathrm{AE}$ events combine and propagate along the waveguide where they are monitored by the sensor at the ground surface. Hence, AE rates produced and measured by the system are proportional to the velocity of slope movement (Equation 1).

The coefficient of proportionality is a measure of the systems sensitivity (i.e. the magnitude of AE rates produced in response to an applied velocity) and is dependent on many variables related to the $\mathrm{AE}$ measurement system such as: the sensor sensitivity controlled by signal amplification and voltage threshold; the depth to the shear surface that influences the magnitude of AE signal attenuation as it is transmitted from the shear zone to ground surface by the waveguide; and active waveguide properties such as the tube geometry and backfill properties. The magnitude of $\mathrm{AE}$ rate responses produced by each measurement system will depend on these factors, in addition to the rate of slope displacement. Through knowledge of the coefficient of proportionality it is possible to convert measured AE rates to quantified velocities. Dixon et al. (2014a) demonstrate how the coefficient of proportionality, if the $\mathrm{AE}$ rate-velocity relationship is assumed to be linear, can be back calculated from slide events. AE rates are the derivative of $\mathrm{AE}$ energy (i.e. cumulative $\mathrm{RDC}$ ) with respect to time, and velocity is the derivative of displacement with respect to time. Therefore, using the shape of the AE rate-time profile it was possible to determine a velocity-time profile for a slope movement event by equating the area under the $\mathrm{AE}$ rate-time curve to the magnitude of displacement measured by an adjacent inclinometer. The total event displacement was distributed proportionately to each trapezoidal integrand under the curve and the velocity over each trapezoid was determined using the displacement/time relation. Each point in time throughout the event subsequently had an AE rate and a corresponding velocity. This enabled derivation of a linear $\mathrm{AE}$ rate-velocity calibration which allowed the velocity and cumulative displacement in subsequent slope deformation events to be quantified by applying the coefficient of proportionality to measured $\mathrm{AE}$ rates (an example is shown in Figure 5 taken from a reactivated slope movement event reported in Dixon et al. 2014a). 


\section{Experimentation}

\subsection{Introduction}

Two series of experiments were conducted using two types of loading apparatus in order to determine a calibration AE rate-velocity relationship for the active waveguide model. Subsequently, a slope failure simulation was performed to establish the validity of using the relationship to quantify slope velocities from measured AE. First, dynamic (low frequency) strain-controlled shear tests were conducted to subject the active waveguide to realistic slope movement ' $S$ ' shaped displacement-time cycles similar to those experienced during reactivated slope movements (e.g. Allison \& Brunsden 1990, Petley et al. 2005 and Dixon et al. 2014a). Second, constant strain rate compression tests were conducted on the active waveguide model using the same apparatus and procedure as Dixon \& Spriggs (2007) in order to validate the results obtained from the dynamic strain-controlled shear tests; the results produced by Dixon \& Spriggs (2007) used a different measurement system (i.e. computer system and not the Slope ALARMS sensor) and therefore the results are not directly comparable with the current AE measurement system. Finally, the dynamic strain-controlled shear test apparatus was used to simulate velocity-time behaviour landslides can experience during first-time failure (i.e. progressively accelerating through order of magnitude changes in velocity) and to assess the proposed method to continuously quantify velocities from monitored AE rates.

The experimental procedure employed was similar to that used by Dixon \& Spriggs (2007). The active waveguide was installed in a flexible geomembrane ( $2 \mathrm{~mm}$ thick high density polyethylene) $130 \mathrm{~mm}$ diameter cylinder to represent the borehole and support provided by the host soil slope. Geomembrane containment was chosen as it provided sufficient rigidity to hold the gravel in place while allowing deformation of the system in a comparable way to an in situ soil surround. The stiffness of the hollow geomembrane cylinder was shown to be negligible over the range of deformations (e.g. up to $10 \mathrm{~mm}$ ) examined. The ring stiffness of the geomembrane cylinder provided constraint (e.g. restricted volume change) equivalent to the in situ surrounding soil (confinement is 
discussed later in this section). A $50 \mathrm{~mm}$ outside diameter steel pipe with $3 \mathrm{~mm}$ wall thickness was used as the waveguide; the same pipe was used by Dixon \& Spriggs (2007) and Dixon et al. (2014a) because $\mathrm{AE}$ stress waves have been shown to propagate along the steel pipe with relatively low attenuation. Soil generated AE stress waves propagate through the soil bulk in 3-dimensions (e.g. longitudinal and shear wave modes) and experience significant attenuation. Upon transmittance into the pipe the waves undergo mode conversion and propagate along the pipe as guided waves and experience relatively low attenuation (e.g. plane longitudinal and flexural waves are detected in the frequency range monitored of 20-30 kHz) (Graff 1975; Maji et al. 1997). Crushed gravel aggregate (photograph in Figure 6) with a nominal particle size of $5 \mathrm{~mm}$ to $10 \mathrm{~mm}$ (the particle size distribution is shown in Figure 7) was used as backfill to produce relatively high energy AE (i.e. relatively large angular particles), and to be consistent with Dixon \& Spriggs (2007) and Dixon et al. (2014a). The backfill was compacted in $0.2 \mathrm{~m}$ high lifts to a density of $1520 \mathrm{~kg} / \mathrm{m}^{3}$ before each test.

The series of experiments described were conducted with dry gravel backfill. The active waveguide will contain ground water below the water table when installed in the field and the backfill will be saturated. The influence of water within the granular soil on the generation of $\mathrm{AE}$ will be influenced in the same way that particle-particle/particle-waveguide interactions will be influenced and is therefore expected to be minimal unless effective stress is significantly reduced (the influence of moisture content on $\mathrm{AE}$ generation in fine grained soil is more significant and is described in Koerner et al. 1981). Attenuation of AE propagating through the backfill (prior to transmittance into the waveguide) is increased if the soil contains water (e.g. Oelze et al. 2002). However, the maximum distance of $\mathrm{AE}$ propagation prior to transmittance into the waveguide is $40 \mathrm{~mm}$ (i.e. the distance between $130 \mathrm{~mm}$ diameter borehole wall and the $50 \mathrm{~mm}$ diameter pipe wall) and the influence of pore-water on the propagation of $\mathrm{AE}$ through the backfill prior to transmission into the waveguide is therefore expected to be small. Conducting the experimental campaign on dry samples therefore provided results representative of the field system, although potentially slightly overestimated the magnitude of $\mathrm{AE}$ rates produced in response to applied deformation rates. Ground water within the 
active waveguide also increases the attenuation of AE stress waves as they propagate along the steel waveguide to the ground surface. This is due to soil covering loss (AE lost from the waveguide as it is transmitted into the surrounding soil, as described in Shiotani \& Ohtsu 1999) increasing with acoustic impedance of the soil (e.g. through increased moisture content). Such losses have been neglected in this study which focused on developing a methodology to quantify deformation rates from measured AE; however, soil cover losses are currently being quantified at Loughborough University in order to determine their influence on the coefficient of proportionality described in Equation 1.

Wooden caps were fitted at each end of the geomembrane cylinder to provide confinement and prevent loss of gravel. Confinement provided to the active waveguide model (i.e. the geomembrane ring stiffness and end caps) will restrict volume change (e.g. the soil will try to dilate inside a relatively constant volume), and will result in increasing confining pressures with the applied load. The increasing confining pressures will result in $\mathrm{AE}$ events of greater magnitude in response to deformation (e.g. Kavanagh 1997 and Michlmayr et al. 2013). AE rates generated will remain proportional to the velocity applied; however, the coefficient of proportionality of the AE ratevelocity relationship is expected to increase with increasing confining pressures (i.e. increasing applied force).

\subsection{Calibration and quantification}

\subsubsection{Dynamic strain-controlled shear tests}

The active waveguide models were oriented horizontally into the loading apparatus and the diameter of the active waveguide was deformed by the loading ram. Figures $8 \mathrm{a}$ to $8 \mathrm{~d}$ show diagrams and photographs of the test setup. The loading ram bearing and base supports were made of internally concave wooden blocks (Figures $8 \mathrm{~b}$ and $8 \mathrm{c}$ ) to accommodate the cylindrical shape of the active waveguide and to distribute the load (i.e. to avoid unrepresentative point loading). Loading was applied vertically by the ram to the centre of the active waveguide. The underlying supports were 
positioned either side of the loading ram in order to induce shearing (two shear zones; one at each side of the loading ram) as this mechanism is representative of the shearing mechanism the active waveguide is subject to in response to slope movement, although there is an additional shear zone in the physical model. The additional shear zone has the potential to result in elevated levels of AE rates in response to deformation, relative to those that would be generated by an active waveguide installed through a slope in the field. Based on experience from the field case studies (e.g. Dixon et al. 2014a) it is not anticipated that the $\mathrm{AE}$ rates generated by the modelled system are unrepresentative of the field system and trends of behaviour are the same. The piezoelectric transducer was consistently placed $0.4 \mathrm{~m}$ from the centre of the loading ram.

A Dartec hydraulically controlled cyclic loading test machine was adapted in order to apply dynamic strain-controlled loading to the active waveguide model. Low frequency cycles of straincontrolled loading with amplitudes (i.e. displacement or stroke) between $1 \mathrm{~mm}$ and $10 \mathrm{~mm}$ were applied to simulate landslide movements (i.e. bell shaped velocity-time profiles where the velocity increases towards a peak value and then decays towards zero when the slope stabilises). The total deformation during the tests was limited to between $1 \mathrm{~mm}$ and $10 \mathrm{~mm}$ to avoid damaging of the geomembrane sleeve, allow repeat testing, and to obtain test results for relatively small displacements (i.e. equivalent to the gravel particle size or smaller). Strain-controlled cyclic frequencies between $0.0001 \mathrm{~Hz}$ (i.e. the lowest allowable by the Dartec machine) and $0.001 \mathrm{~Hz}$ were selected to replicate realistic cycles of movement that soil slopes undergo; up to velocities of approximately $100 \mathrm{~mm}$ per hour. LabView was used to record the displacement- and load-time behaviour of the active waveguide throughout the tests and velocity-time was determined later through calculating the rate of change of the displacement-time curve.

The AE rate response of the active waveguide models to the strain-controlled dynamic loading was captured using the Slope ALARMS sensor with a comparator (i.e. voltage threshold) level of 0.25 $\mathrm{V}$ to ensure that no mechanical or electrical background noise was recorded (i.e. the amplitude of background noise signals fell below a $0.25 \mathrm{~V}$ threshold and were therefore not detected). RDC were 
recorded and time stamped every 5 seconds throughout each test and these RDC per 5 second AE rates were converted to conventional RDC per hour values. A total of 21 tests were conducted; with displacement-time cyclic functions ranging from $1 \mathrm{~mm}$ amplitude with $0.0001 \mathrm{~Hz}$ frequency to 10 mm amplitude with $0.001 \mathrm{~Hz}$ frequency.

Figures 9a to $9 \mathrm{~d}$ show the results from an applied displacement-time function of $4 \mathrm{~mm}$ amplitude and $0.0003 \mathrm{~Hz}$ frequency. Of interest is the $\mathrm{AE}$ rate response and its resemblance to the applied velocity throughout the test (Figure 9c); suggesting a proportional relationship exists between them. The sensitivity of the AE rate response to changes in applied velocity demonstrates the promise of the system to be able to detect destabilising effects (e.g. slope velocity increasing in response to prolonged rainfall) and stabilising effects (e.g. slope velocity decreasing subsequent to remediation measures), and as an early warning system to detect accelerations of slope movements continuously and in real-time. Note that there is a time lag of roughly 1 minute between the sudden increase in velocity and the initiation of the $\mathrm{AE}$ rate response; this is hypothesised to be due to the initial portion $(<0.2 \mathrm{~mm})$ of the displacement being taken up by the geomembrane sleeve prior to deformation of the gravel column taking place. The active waveguide model was prepared and compacted vertically and end caps were secured before the specimen was placed horizontally into the test apparatus. Slight lateral displacement of the gravel occurred when placed horizontally as it was difficult to secure the end caps sufficiently to prevent small displacement. This problem does not occur in the field as: the active waveguide is installed vertically through the slope, backfill is compacted sufficiently in lifts and is in direct contact with the host soil slope, and normal stress is provided by the unit weight of the backfill.

A relationship between the velocity applied and the $\mathrm{AE}$ rates produced can be determined from the test example shown in Figure 9c. It was possible to produce 'measured' AE rate vs. velocity calibration relationships, such as shown in Figure 10, by calculating 2 minute moving average values of velocity and $\mathrm{AE}$ rates throughout the test. The lower section of the 'loop' curve in Figure 10 is produced from increasing velocity (i.e. the first half of the bell shaped curve in Figure 9c) and this 
approaches the peak velocity that was applied. The upper section of the 'loop' curve is produced from decreasing velocity (i.e. the second half of the bell shaped curve in Figure 9c). The magnitude of AE rates produced in response to increasing velocity was less than those produced from decreasing velocity. This is hypothesised to be due to a combination of: an initial portion of the displacement $(<0.2 \mathrm{~mm})$ at the start of the test being taken up by the geomembrane sleeve prior to initiation of deformation of the gravel column; a small magnitude of deformation in the gravel column was required to mobilise particle-particle/particle-waveguide interactions and generate $\mathrm{AE}$ during the initial period of the test; the rate of particle-particle/particle-waveguide interactions were sustained (i.e. remained elevated) at the onset of reducing velocity prior to the rate of interactions responding and reducing; and the coefficient of proportionality increased (i.e. AE rates generated in response to an applied velocity increased) with increasing confining pressures throughout the test. The 'calculated' AE rate vs. velocity relationship shown in Figure 10 was determined using the back calculation method detailed by Dixon et al. (2014a) and described in Section 2; the magnitude of total deformation (i.e. $4 \mathrm{~mm}$ in this case) was equated to the area under the $\mathrm{AE}$ rate-time curve (i.e. the grey line shown in Figures $9 \mathrm{~b}$ to $9 \mathrm{~d}$ ) and was distributed proportionately to each trapezoidal integrand under the curve and the velocity over each trapezoid was determined using the displacement/time relation. These 'calculated' velocities were then plotted against the measured AE rates to produce the linear AE rate vs. velocity 'calculated' relationship shown in Figure 10 which passes directly through the centre of the measured relationship; this validates the back calculation calibration method described by Dixon et al. (2014a), although it assumes the relationship to be linear.

Figure 11 shows the force vs. displacement relationships for selected $1 \mathrm{~mm}, 4 \mathrm{~mm}$ and $10 \mathrm{~mm}$ amplitude dynamic strain-controlled shear tests on active waveguide models. The same forcedisplacement behaviour was experienced in each test demonstrating that each sample was prepared and tested in a consistent manner. The gradual increase in gradient of the relationships in Figure 11 is explained by a combination of: increasing confining pressures increasing the shear resistance of the gravel; and at displacements of approximately $4-6 \mathrm{~mm}$ the shear resistance of the steal waveguide is gradually introduced within the active waveguide system (i.e. increasing the system stiffness). 


\subsubsection{Determination of the coefficient of proportionality}

Figures 12 and 13 show the measured AE rate-velocity relationship established using data from the 21 dynamic strain-controlled shear tests on active waveguide models with gravel aggregate backfill as described in Section 3.2.1. The plots were produced from collating all 'measured' AE rate vs. velocity relationships (i.e. Figure 10) from each of the 21 tests. The landslide velocity scale after Anderson \& Holcombe (2013, p92) is superimposed in Figure 13, which is plotted on logarithmic scales, to demonstrate the range of realistic slope displacement rates that have been examined. Determination of an equation to describe the relationship was conducted by plotting a linear regression line through the AE rate-velocity relationship in Figure 12. It is anticipated that determination of this relationship will allow measured AE rates to be converted into velocities continuously and in real-time throughout subsequent tests. The equation for the linear relationship is detailed in Equation 2; the linear regression produced an $\mathrm{R}^{2}$ value of 0.82 which indicates a strong positive linear correlation.

$$
\begin{aligned}
& \mathrm{AE}_{\text {rate }}=\left(4.4 \times 10^{5}\right) \times \text { Velocity } \\
& \therefore \mathrm{C}_{\mathrm{p}}=4.4 \times 10^{5} \\
& \text { and Velocity }=\left(2.3 \times 10^{-6}\right) \times \mathrm{AE}_{\text {rate }}
\end{aligned}
$$

The AE rate-velocity relationship is influenced by confining pressure and the variability in Figure 12 could be a function of this. However, for the purpose of this study a simple linear regression was selected to define the empirical $\mathrm{AE}$ rate-velocity relationship because the aim was to demonstrate that velocity could be quantified to better than an order of magnitude (i.e. for use in a robust $\mathrm{AE}$ early warning system). It is anticipated that greater accuracy could be achieved through development of the AE rate-velocity relationship to be a function of confining pressure. The linear relationship was established for the range of velocities examined but it should be noted that the data in Figure 12 
appears to be slightly non-linear and therefore the AE rate-velocity relationship may become nonlinear over a greater range of applied velocities.

\subsubsection{Constant strain rate compression tests}

Constant strain rate compression tests using the same test apparatus as Dixon \& Spriggs (2007) were conducted in an attempt to validate the results produced from the dynamic strain-controlled shear tests. Dixon \& Spriggs (2007) used a different AE measurement system and therefore it was necessary to conduct an additional series of compression tests using the Slope ALARMS sensor for comparison. The same active waveguide model used in the dynamic strain-controlled shear tests was used in the constant strain rate compression tests. It should be noted that the mode of deformation of the active waveguide is compression in these tests rather than the double shear mechanism used in the dynamic strain-controlled tests. Figure 14 shows a photograph of the active waveguide installed in the test apparatus. 20 tests were conducted at a constant displacement rate of $66.15 \mathrm{~mm}$ per hour, 10 tests were conducted at $5.88 \mathrm{~mm}$ per hour, and 10 tests were conducted at $0.706 \mathrm{~mm}$ per hour. The displacement rates selected were the same as those used by Dixon \& Spriggs (2007) and are separated by orders of magnitude. The results from the 40 tests can be seen in Figure 15, and the data sets coalesce into groups governed by the displacement rate that was applied (as detailed in Dixon \& Spriggs (2007)). The average AE rate produced from each test was plotted against the applied velocity in Figure 13 (triangle data points). The data fall into the AE rate vs. velocity relationship determined from the dynamic strain-controlled shear tests; this validates the data produced from the dynamic strain-controlled shear tests and suggests that the mechanism of loading (i.e. shear or compression) does not yield a significant difference in the AE rates produced from the system.

\subsubsection{Quantification of velocities during slope failure simulation}


The dynamic strain-controlled shear test apparatus was programmed to apply an accelerating displacement-time function to the active waveguide model similar to those experienced by deforming slopes as they undergo failure. The total displacement applied throughout this test was $10 \mathrm{~mm}$. The first $1 \mathrm{~mm}$ of displacement was applied at a frequency of $0.0001 \mathrm{~Hz}$, the second $1 \mathrm{~mm}$ of displacement at $0.0002 \mathrm{~Hz}$, the third at $0.0003 \mathrm{~Hz}$ and so on. The final (tenth) $1 \mathrm{~mm}$ of displacement was applied at a frequency of $0.001 \mathrm{~Hz}$. This generated the results shown in Figures 16a to 16c. The recorded $\mathrm{AE}$ rates (recorded over 5 second intervals) were converted to velocity values using Equation 2 and are shown in Figure 16c as the black line. Figures 17a to 17c show 2 minute moving average values (i.e. to smooth the sporadic nature of the raw 5 second interval $\mathrm{AE}$ data). The results demonstrate that it is possible to quantify applied velocities from measured active waveguide generated $\mathrm{AE}$ rates continuously throughout the event with accuracy better than an order of magnitude and in line with standard landslide displacement rate classifications: both calculated and measured velocities fall into the same velocity classification (e.g. 'slow' and 'moderate') throughout the increasing velocity stages of the experiment in Figure 17b. The sensitivity of the AE rate response to changes in applied velocity demonstrates promise of the system to be able to detect destabilising and stabilising behaviour, and as an early warning system to detect accelerations of movements continuously and in real-time during progressive failure.

Of particular note is the surge in velocity (i.e. sudden acceleration) that occurred between 14 minutes and 16 minutes as can be seen in Figures $16 \mathrm{c}, 17 \mathrm{a}$ and $17 \mathrm{~b}$. The AE rates immediately responded to the increase in velocity and also increased significantly. As the rate of increase in velocity reduced (i.e. gradient of the velocity-time curve reduced) at 16 minutes the $\mathrm{AE}$ rates also responded and the rate of increase of $\mathrm{AE}$ rates reduced (i.e. gradient of the $\mathrm{AE}$ rate-time curve reduced).

Figure $17 \mathrm{c}$ shows the error (i.e. difference between the calculated and measured velocity) from the 2 minute moving average values throughout the test. The error is consistently less than $+/-5 \mathrm{~mm} /$ hour except for the periods in which; the surge in velocity occurred (at approximately 14-16 minutes), and 
when the velocity suddenly reduced (at 23 minutes) at the end of the test. The calculated values (i.e. derived from AE) overestimated the velocity for these periods. It is expected that the surge in velocity induced a combination of inter-particle friction, contact stress release and force chain buckling (Michlmayr et al. 2013) and therefore resulted in a period of relatively high AE activity and an overestimation in calculated velocity. The overestimation of the calculated velocity at the reduction in measured velocity at the end of the test is anticipated to be due to the same phenomena described in Section 3.2.1: the rate of particle-particle/particle-waveguide interactions were sustained (i.e. remained elevated) at the onset of reducing velocity prior to the rate of interactions responding and reducing; and the applied load began to reduce at approximately 24 minutes which resulted in changed confining pressures and altered the value of $\mathrm{C}_{\mathrm{p}}$. These error values are considered small and demonstrate the ability of the system and the technique to quantify slope displacement rates from measured AE rates with accuracy in line with standard classification of landslide movements (i.e. Figure 2 and Figure 17b). It is anticipated that these errors could be reduced further if the AE ratevelocity relationship was to be refined through further experimentation. The calculated velocity (i.e. derived through application of the coefficient of proportionality to measured AE rates) is plotted against the measured applied velocity throughout the landslide failure simulation experiment in Figure 18. The linear regression in Figure 18 produced an $\mathrm{R}^{2}$ value of 0.96 which demonstrates a very strong linear correlation. The gradient of the linear trend line in Figure 18 is 1.05 which highlights that the velocity quantified from measured $\mathrm{AE}$ rates (i.e. calculated velocity) was slightly greater than the measured velocity throughout the experiment. This information could be used to refine the value of the coefficient of proportionality for use in subsequent tests.

\section{Additional considerations and ongoing research}

The majority of the variables that influence the coefficient of proportionality of the AE rate vs. velocity relationship for the active waveguide system (e.g. sensor sensitivity and distance between sensor and shear surface) were kept constant throughout the experimentation described in this paper, aside from the velocity and load applied. This study was conducted to confirm that AE rates produced 
from the active waveguide system are proportional to the velocity applied during slide events, and to establish an AE rate vs. velocity calibration relationship for use in quantifying applied velocities from measured $\mathrm{AE}$ rates. The range of velocities examined in the present study was 0 to $100 \mathrm{~mm} / \mathrm{hour}$ (i.e. up to 'moderate' velocities equivalent to $2.4 \mathrm{~m}$ /day), with little control over velocities below 'slow'. Field studies (e.g. Dixon et al. 2014a) have demonstrated performance of the system at displacement rates below 'slow'; however, further experimentation is required to assess performance at rates above 'moderate'. The influences of each of the variables that define the coefficient of proportionality are currently being investigated to quantify them. Both dynamic strain-controlled shear tests and constant strain rate compression tests have been conducted on active waveguide models with a variety of other backfill materials (i.e. a range of particle sizes, gradations and shapes); the results demonstrate the same trends in behaviour (i.e. AE rates generated are proportional to the velocity applied) and confirm that greater magnitude events are generated by large angular particles. The implications of this are: a range of backfill materials can be used to suit requirements; and there is potential to monitor $\mathrm{AE}$ generated from the in situ soil slope in cases where the in situ material contains a high percentage of coarse-grained particles. A driven passive waveguide would have to be used in these applications to ensure intimate contact between the waveguide and in situ soil that is generating AE.

It is important to note that the mechanisms of stress application in the experiments described are not equal to those generated by slope movements; however, the behaviour and $\mathrm{AE}$ response is comparable as demonstrated by field monitoring in Dixon et al. (2014a). Also, the change in shape of the active waveguide due to deformation is hypothesised to influence the $\mathrm{AE}$ rates produced in response to movements. Therefore, a freshly installed active waveguide is expected to generate a different $\mathrm{AE}$ rate response (in terms of actual values) to one that has already been subjected to substantial deformations, although trends of behaviour would be similar and comparable (i.e. proportional to the velocity of slope movement but with a different coefficient of proportionality). This is because the interactions between all of the elements changes at large displacements.

\section{Summary}


The paper summarises the use of active waveguides as subsurface instrumentation to monitor $\mathrm{AE}$ generated in response to slope movements, and to assess the stability of soil slopes. Previous field trials and laboratory experiments reported by the authors have demonstrated that $\mathrm{AE}$ rates generated by active waveguides are proportional to the velocity of slope movement, and velocities can be differentiated by orders of magnitude, which is consistent with standard landslide movement classification. Results from dynamic strain-controlled shear loading experiments conducted on full scale active waveguide physical models were presented and the results confirmed that $\mathrm{AE}$ rates generated are proportional to the rate of slope movement, and the coefficient of proportionality that defines the $\mathrm{AE}$ rate vs. velocity relationship has been quantified (e.g. $4.4 \times 10^{5}$ for the angular gravel backfill investigated). The authors demonstrated that slope velocities can be quantified continuously in real-time through monitoring active waveguide generated AE during a slope failure simulation. The study shows that the technique can quantify landslide velocity to better than an order of magnitude and can therefore be used to provide an early warning of slope instability through detecting and quantifying accelerations of slope movement.

Operation of a unitary battery operated AE rate sensor (Slope ALARMS) is detailed in the paper, which can provide relatively low cost continuous real-time slope monitoring. Active waveguides and Slope ALARMS sensors are being trialled at various natural and man-mode slopes throughout the UK, Italy, Austria and Canada in order to assess performance in the field environment and compare against other deformation monitoring instruments.

\section{Acknowledgements}

The Authors would like to acknowledge the contribution of Phillip Meldrum and Edward Haslam of the British Geological Survey for their involvement in the development of the Slope ALARMS sensor. The Loughborough University Graduate School provided funding for the PhD studies of Alister Smith. 


\section{References}

Allison, R J, and D Brunsden. 1990. Some Mudslide Movement Patterns. Earth Surface Processes and Landforms 15: 297-311.

Anderson, M G, and E Holcombe. 2013. Community-Based Landslide Risk Reduction: Managing Disasters in Small Steps. World Bank Publications. p92-93

Beard, F D. 1961. Predicting Slides in Cut Slopes. Western Construction: 72.

Cadman, J D, and R E Goodman. 1967. Landslide Noise. Science 158: 1182-1184.

Chichibu, A. Jo, K. Nakamura, M. Goto, T. and M Kamata. 1989. Acoustic Emission Characteristics of Unstable Slopes. Journal of Acoustic Emission 8 (4): 107-112.

Cruden, D., \& Varnes, D. J. 1996. Landslide types and processes. Landslides: investigation and mitigation, 247, 36-75.

Dixon, N. Hill, R. \& Kavanagh, J. 2003. Acoustic emission monitoring of slope instability: Development of an active wave guide system. Institution of Civil Engineers Geotechnical Engineering Journal, $156,2,83-95$.

Dixon, N. \& Spriggs, M. 2007. Quantification of slope displacement rates using acoustic emission monitoring. Canadian Geotechnical Journal, 44, 6, 966-976.

Dixon, N. \& Spriggs, M. 2011. Apparatus and method for monitoring soil slope displacement rate. UK Patent Application GB 2467419A, Awarded May 2011. 
Dixon, N, M P Spriggs, P Meldrum, and E Haslam. 2012a. Field Trial of an Acoustic Emission Early Warning System for Slope Instability. In Landslides and Engineered Slopes: Protecting Society through Improved Understanding, 1399-1404.

Dixon, N, M P Spriggs, G Marcato, and A Pasuto. 2012b. Landslide Hazard Evaluation by Means of Several Monitoring Techniques, Including an Acoustic Emission Sensor. In Landslides and Engineered Slopes: Protecting Society through Improved Understanding, 1405-1411.

Dixon, N, M P Spriggs, A Smith, P Meldrum, and E Haslam. 2014a. Quantification of Reactivated Landslide Behaviour using Acoustic Emission Monitoring. Landslides, 1-12. DOI: 10.1007/s10346014-0491-z

Dixon, N, R Moore, M P Spriggs, A Smith, P Meldrum, and R Siddle. 2014b. Performance of an Acoustic Emission Monitoring System to Detect Subsurface Ground Movement at Flat Cliffs, North Yorkshire, UK. In IAEG XII Congress - Torino.

Fujiwara, T, A Ishibashi, and K Monma. 1999. Application of Acoustic Emission Method to Shirasu Slope Monitoring. In Slope Stability Engineering, Yagi, Yamagami \& Jiang, Balkema, Rotterdam, $147-150$.

Garga, V K, and A Chichibu. 1990. A Study of AE Parameters and Shear Strength of Sand. Progress in Acoustic Emission V: 129-136.

Graff, K F. 1975. Wave Motion in Elastic Solids. Courier Dover Publications: p79-141.

Hutchinson, J N. 1988. General Report: Morphological and Geotechnical Parameters of Landslides in Relation to Geology and Hydrogeology. In Proc 5th International Symposium on Landslides, Lausanne, 3-35. 
Kavanagh, J. 1997. The use of acoustic emission to monitor the deformation of a soil body. $\mathrm{PhD}$ thesis, Nottingham Trent University.

Koerner, R.M. McCabe, W.M. \& Lord, A.E. 1981. Acoustic emission behaviour and monitoring of soils. In Acoustic Emission in Geotechnical Practice, ASTM STP 750, pp. 93-141.

Koerner, R M, A E Lord, and W L Deutsch. 1984a. Determination of Prestress in Granular Soils Using AE. Journal of Geotechnical Engineering 110 (3): 346-359.

Koerner, R M, A E Lord, and W L Deutsch. 1984b. Determination of Prestress in Cohesive Soils Using AE. Journal of Geotechnical Engineering 110 (11): 1537-1549.

Leroueil, S. 2001. Natural Slopes and Cuts: Movement and Failure Mechanisms. Geotechnique 51 (3): $197-243$.

Lord, A E, and R M Koerner. 1974. Acoustic Emission Response of Dry Soils. Testing and Evaluation (ASTM) 2: 159-162.

Maji, A K, D Satpathi, and T Kratochvil. 1997. Acoustic Emission Source Location Using Lamb Wave Modes. Journal of Engineering Mechanics 123: 154-161.

Michlmayr, G., Cohen, D., \& Or, D. 2012a. Sources and characteristics of acoustic emissions from mechanically stressed geologic granular media - A review. Earth-Science Reviews, 112, 97-114.

Michlmayr, G, D Or, and D Cohen. 2012b. Fiber Bundle Models for Stress Release and Energy Bursts during Granular Shearing. Physical Review 86 (061307): 1-7. 
Michlmayr, G., Cohen, D., \& Or, D. 2013. Shear-induced force fluctuations and acoustic emissions in granular material. Journal of Geophysical Research: Solid Earth, 118(12), 6086-6098.

Mitchell, R J, and P M Romeril. 1984. Acoustic Emission Distress Monitoring in Sensitive Clay. Canadian Geotechnical Journal 21: 176-180.

Naemura, S, Mitugu T, Nishikawa, Nakamura M, K Jo, and T Kishishita. 1991. Acoustic Emission of Penetration Experiments to Judge Soil Condition. Journal of Acoustic Emission 10 (1-2): 55-58.

Nakajima, I., Negishi, M., Ujihira, M., \& Tanabe, T. (1991). Application of the acoustic emission monitoring rod to landslide measurement. 5th conference on acoustic emission / microseismic activity in geologic structures and materials (pp. 1-15).

Oelze, M L, W D O’Brien, and R G Darmody. 2002. Measurement of Attenuation and Speed of Sound in Soils. Soil Science Society of America Journal 66 (3): 788-796.

Petley, D N, F Mantovani, M H Bulmer, and A Zannoni. 2005. The Use of Surface Monitoring Data for the Interpretation of Landslide Movement Patterns. Geomorphology 66: 133-147.

Petley, D N. 2012. Global Patterns of Loss of Life from Landslides. Geology, Geological Society of America 40 (10): 927-930.

Rouse, C, P Styles, and S A Wilson. 1991. Microseismic Emissions from Flowslide-Type Movements in South Wales. Engineering Geology 31: 91-110.

Shiotani, T. \& Ohtsu, M. 1999. Prediction of slope failure based on AE activity. In Acoustic Emission: Standards and Technology update (Vahaviolos, S.J. (Ed.)), American Society for Testing Materials, ASTM STP, Pennsylvania, 1353, pp. 157-172.

Schuster, R.L. \& Krizek, R.J. (eds.) 1978. Landslides Analysis and Control, Schuster \& Krizek Special Report 176, National Academy of Science, Washington. 
Smith, A, N Dixon, N Berg, A Take, and D Proudfoot. 2014. Listening for Landslides: Method, Measurements and the Peace River Case Study. In Geohazards 6. 
Table 1. Influence of soil properties on AE behaviour (summarised after Keorner at al. 1981 and Dixon et al. 2003)

\begin{tabular}{|c|c|c|}
\hline & Property & Influence on AE behaviour \\
\hline \multirow[t]{3}{*}{ Granular soil } & $\begin{array}{l}\text { Coefficient of } \\
\text { uniformity }\end{array}$ & $\begin{array}{l}\text { Soils with better grading and larger values of coefficient of } \\
\text { uniformity produce greater AE. }\end{array}$ \\
\hline & Particle shape & Angular particles generate more $\mathrm{AE}$ than rounded particles. \\
\hline & Particle size & $\begin{array}{l}\text { Soils with larger particles generate AE with greater amplitude than } \\
\text { those with smaller particles; however, smaller particles give rise to } \\
\text { a greater number of AE events (due to a greater number of particle- } \\
\text { to-particle contacts). }\end{array}$ \\
\hline \multirow[t]{2}{*}{$\begin{array}{l}\text { Fine-grained } \\
\text { soil }\end{array}$} & Plasticity index & $\begin{array}{l}\text { The higher the plasticity index the lower the AE response of the } \\
\text { soil. This is partly due to the higher clay content (i.e. greater } \\
\text { proportion of 'quiet' soil grains) found in high plasticity soils. The } \\
\text { influence of clay mineralogy is yet to be investigated. }\end{array}$ \\
\hline & Water content & $\begin{array}{l}\text { The higher the water content, and thus lower the strength, the } \\
\text { lower the AE response. }\end{array}$ \\
\hline \multirow[t]{2}{*}{$\begin{array}{l}\text { General } \\
\text { factors }\end{array}$} & Soil structure & $\begin{array}{l}\text { The majority of research has been conducted on remoulded } \\
\text { samples and therefore the AE response of samples containing } \\
\text { discontinuities (e.g. fissures) has not yet been investigated. It is } \\
\text { anticipated that the soil structure will have a significant influence } \\
\text { on the AE generated, and therefore understanding the influence of } \\
\text { soil structure will be important when interpretation of AE from } \\
\text { undisturbed soil is required. }\end{array}$ \\
\hline & Stress history & $\begin{array}{l}\text { Due to the Kaiser effect soils have been shown to exhibit greatly } \\
\text { increased AE activity when stress levels exceed the pre-stress/pre- } \\
\text { consolidation pressure (e.g. Koerner et al. 1984a and Koerner et al. } \\
\text { 1984b). }\end{array}$ \\
\hline
\end{tabular}




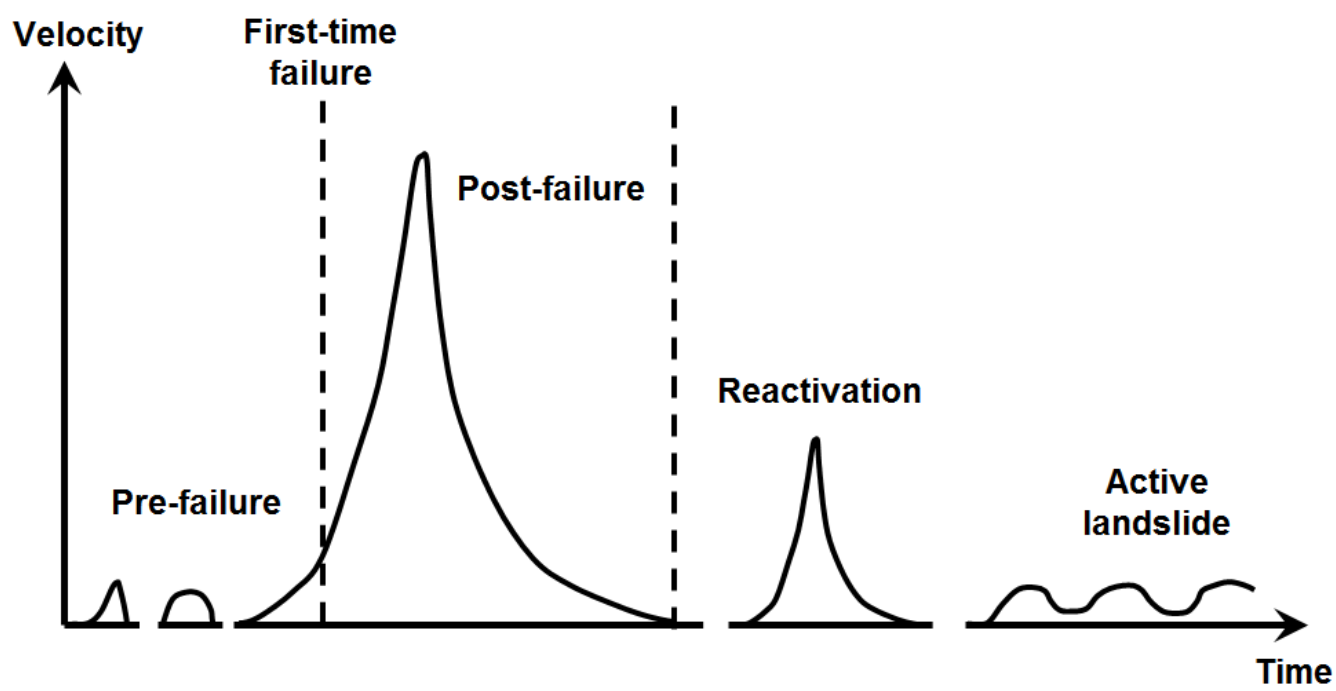

Figure 1. Stages of landslide movement after Leroueil (2001)

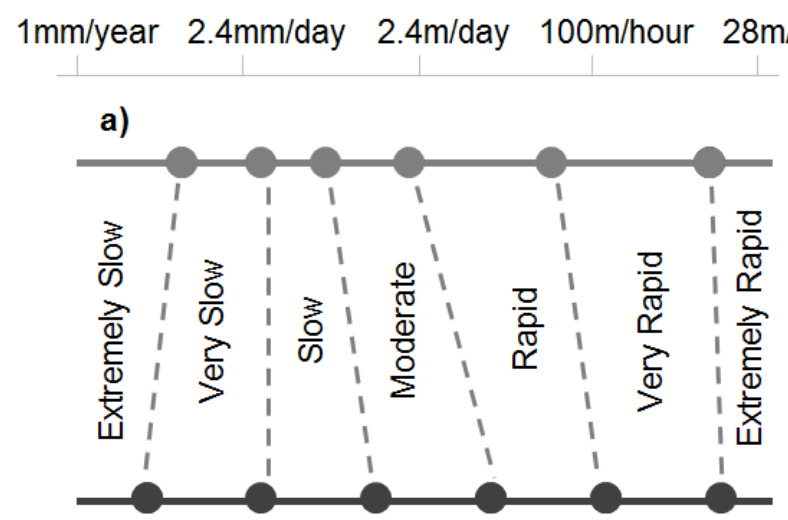

b)

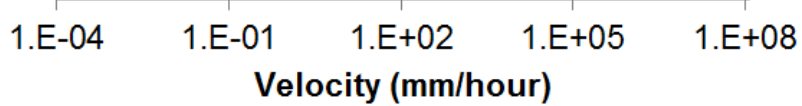

Figure 2. Landslide velocity scales taken from; a) Schuster \& Krizek (1978) and b) Cruden \& Varnes (1996) and Anderson \& Holcombe (2013, p92) (after Smith et al. 2014) 


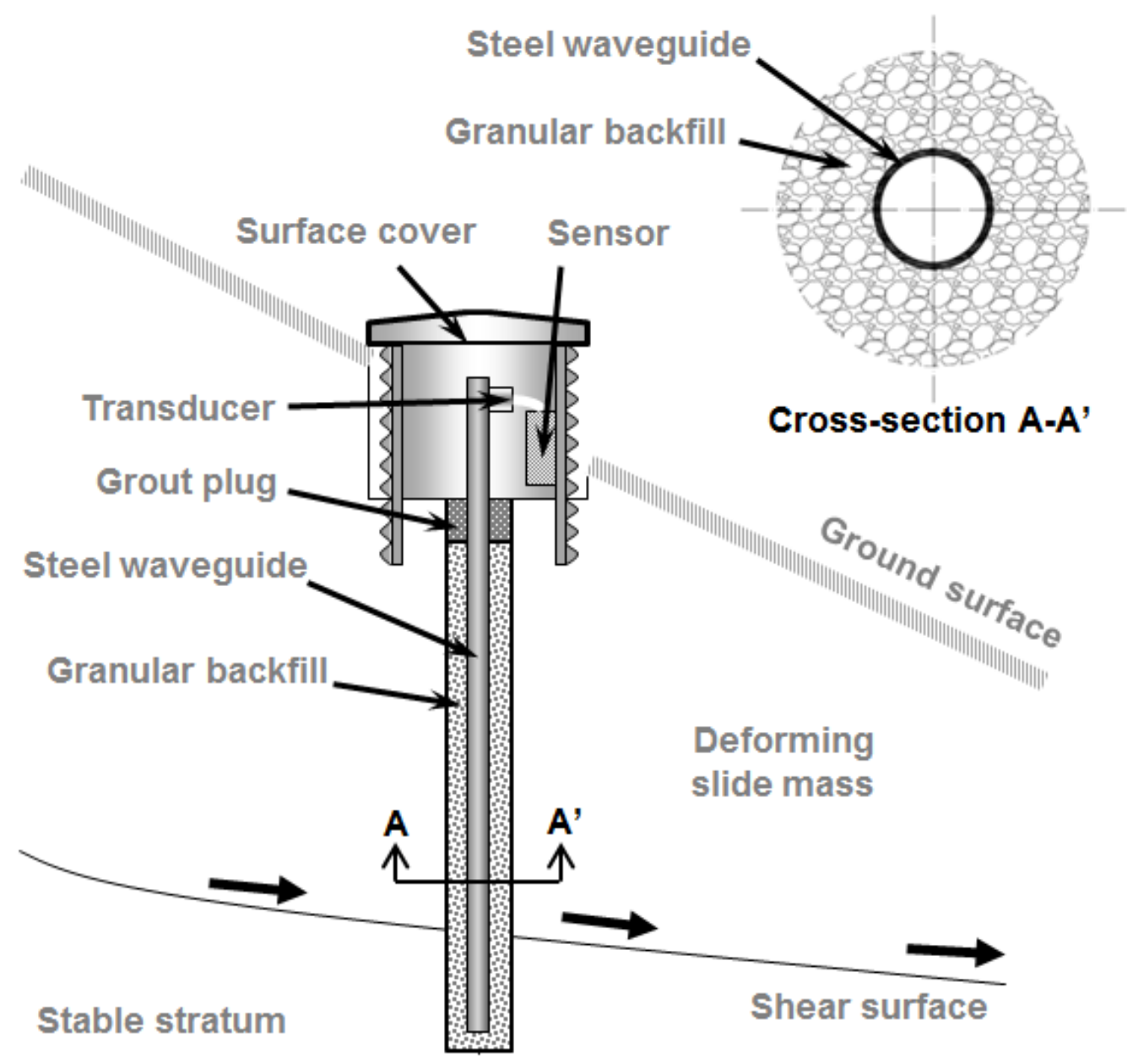

Figure 3. Schematic of an active waveguide installed through a slope with an ALARMS sensor connected at the ground surface (after Dixon et al. 2012a) 


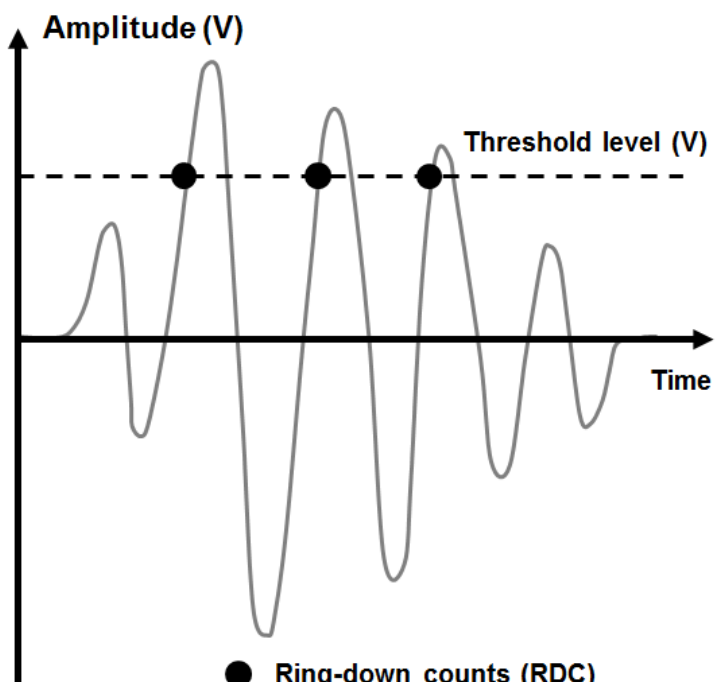

Figure 4. Simplified example AE event waveform with ring-down counts (RDC) defined

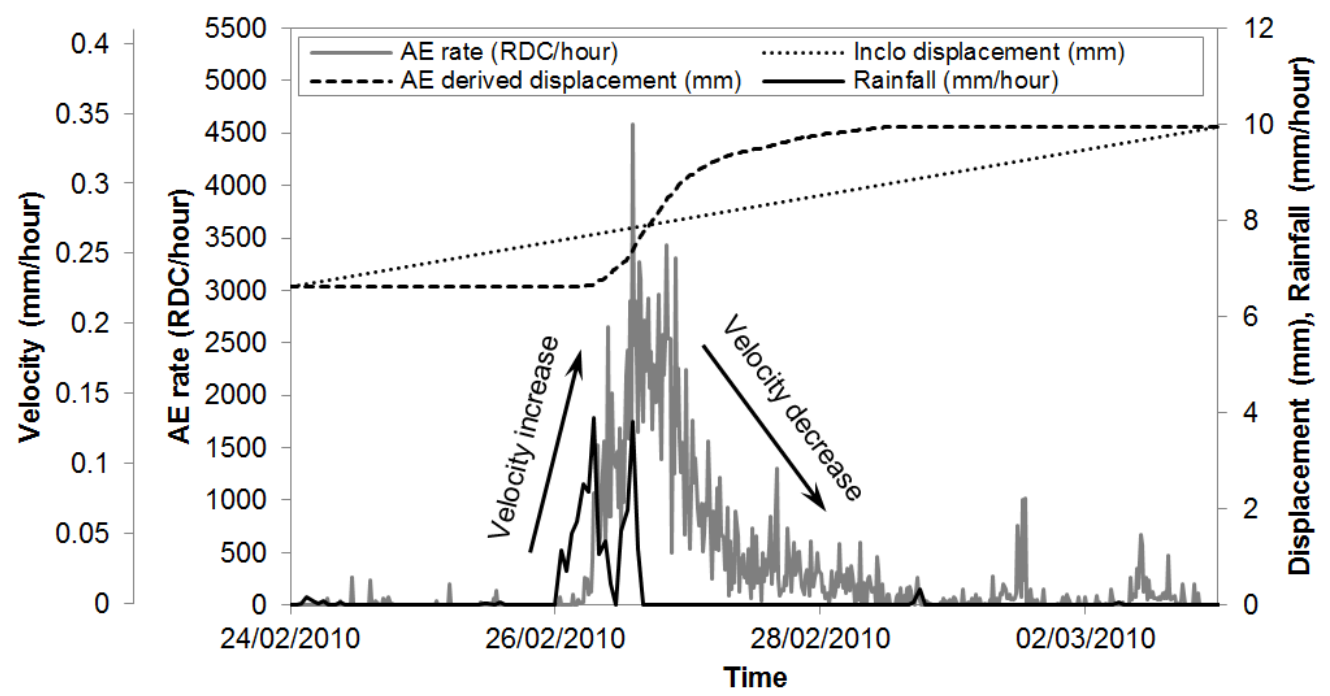

Figure 5. AE rate-, AE derived velocity-, inclinometer measured displacement-, AE derived displacement- and rainfall-time series for a reactivated slope deformation event after Dixon et al. 


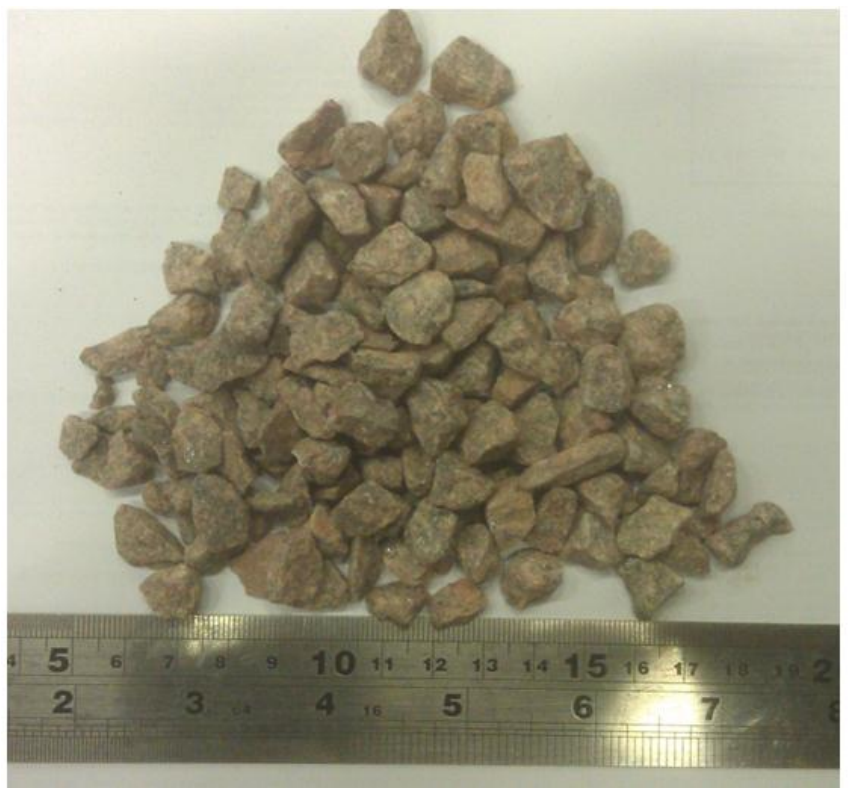

Figure 6. Photograph of angular gravel aggregate

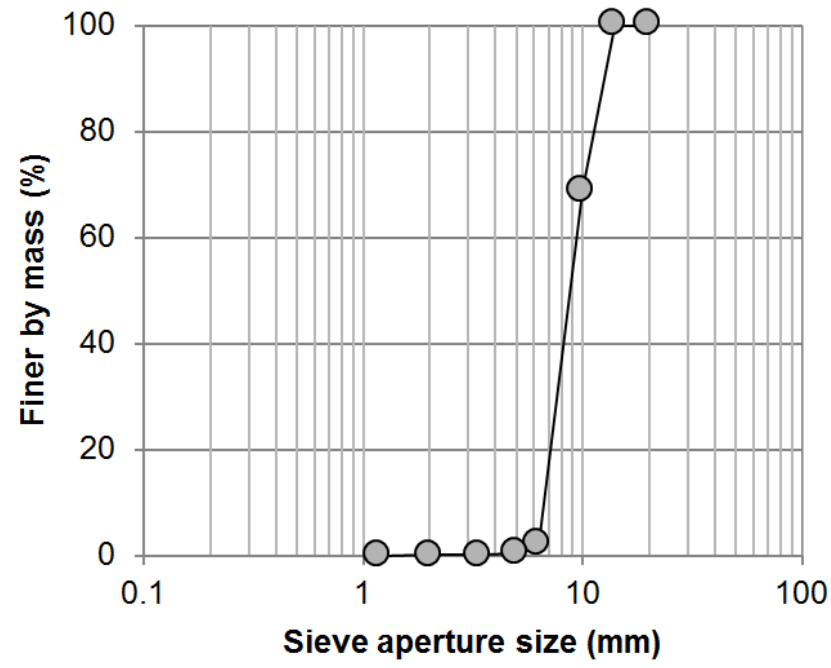

Figure 7. Particle size distribution of angular gravel aggregate 
a)

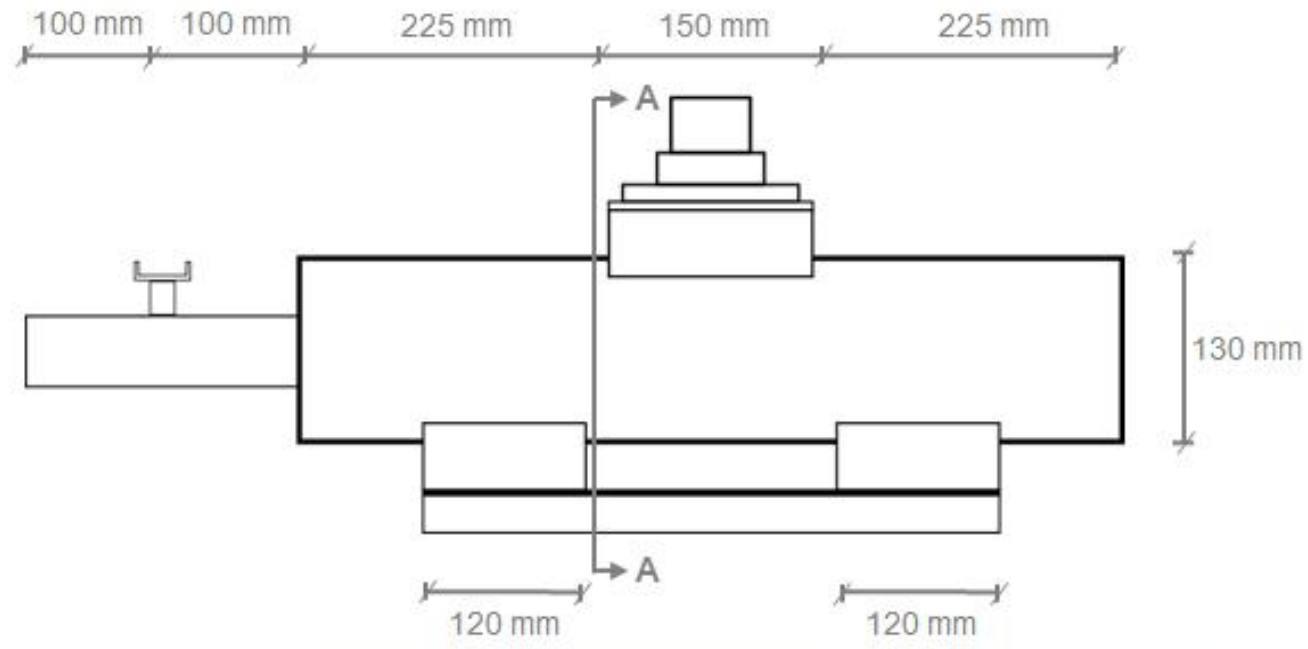

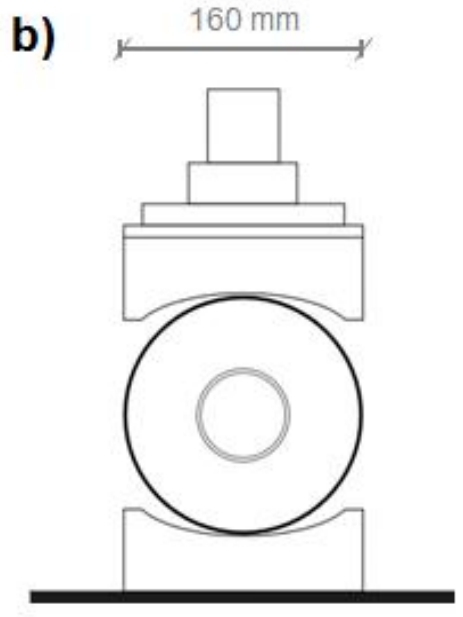

Section A

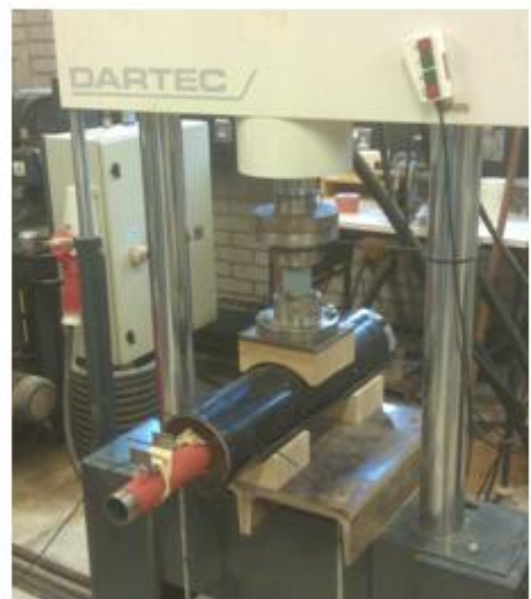

c)

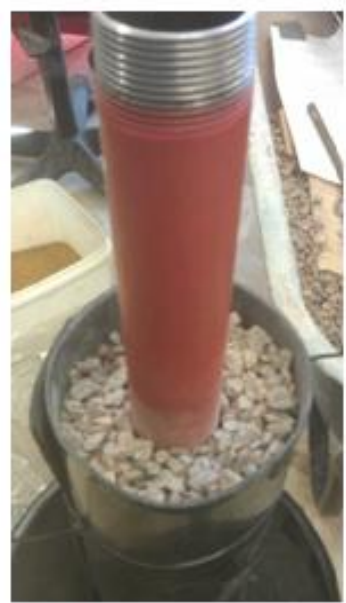

d)

Figure 8. a) Elevation schematic of active waveguide specimen installed in dynamic strain-controlled shear apparatus, b) cross section schematic of active waveguide specimen installed in apparatus, c) photograph of test set up, and d) photograph of active waveguide model with angular gravel aggregate backfill 

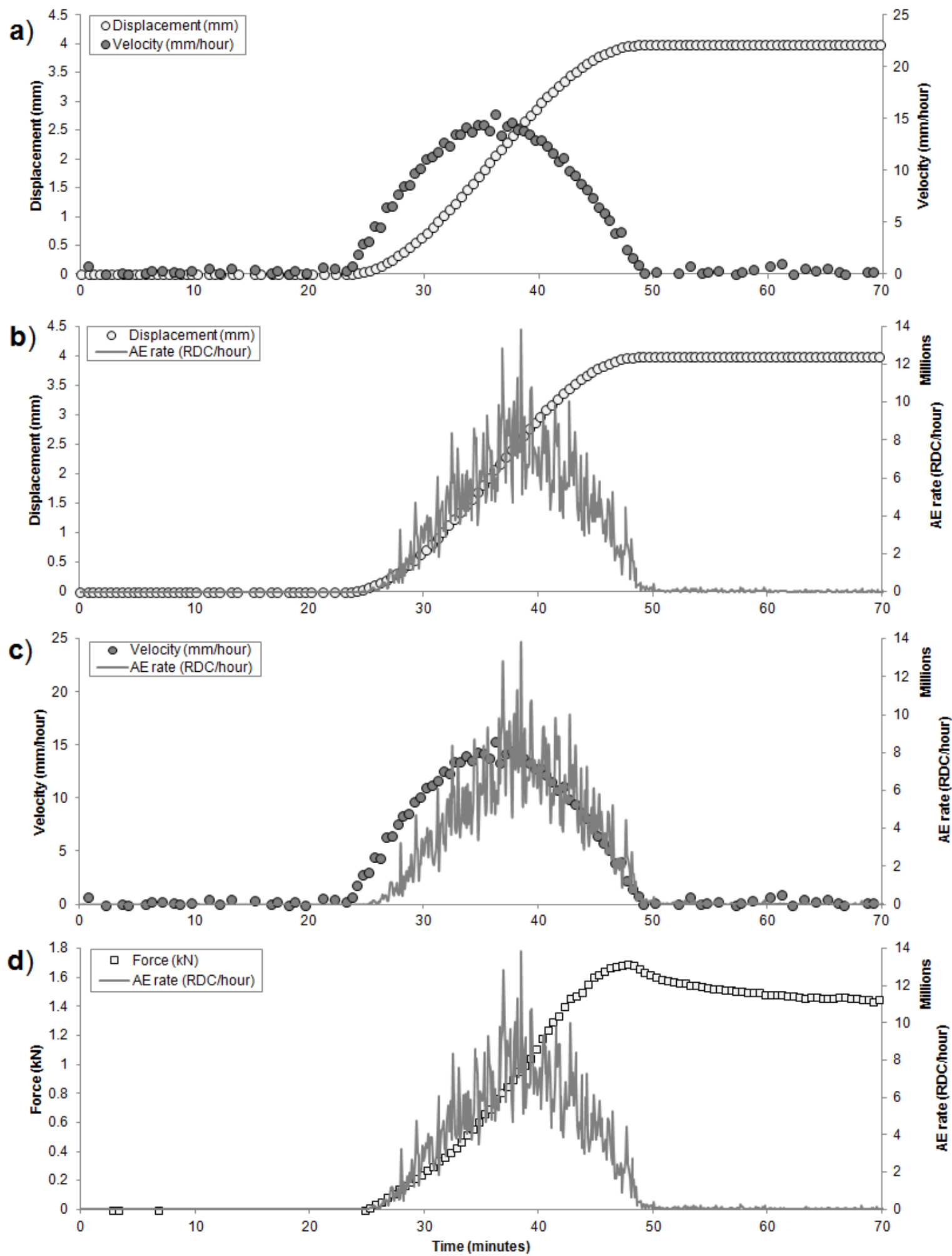

Figure 9. Time series from a dynamic strain-controlled shear test; a) displacement- and velocity-time,

b) displacement- and $\mathrm{AE}$ rate-time, c) velocity- and $\mathrm{AE}$ rate-time, and d) force- and $\mathrm{AE}$ rate-time 


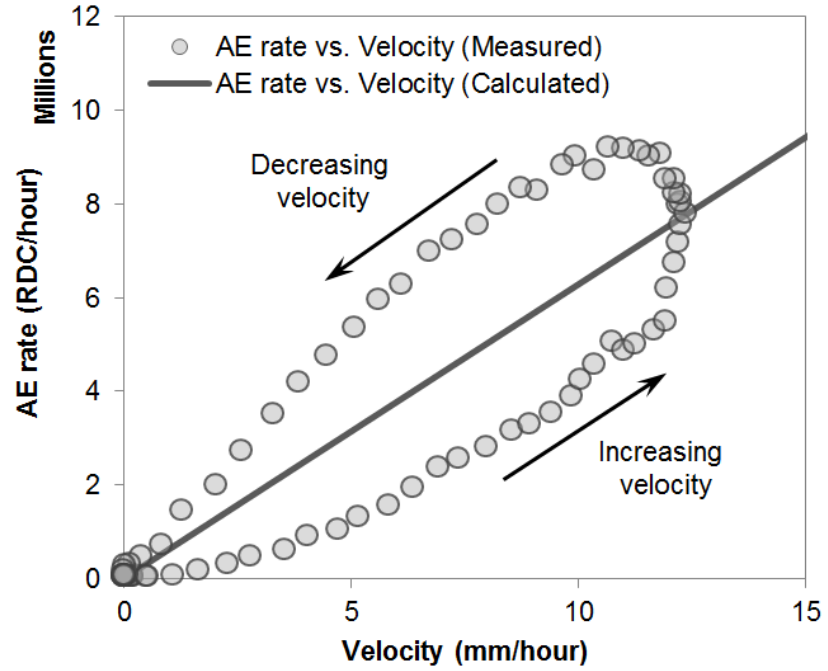

Figure 10. Measured and calculated AE rate vs. applied velocity relationships determined from one dynamic strain-controlled shear test (2 minute moving average values)

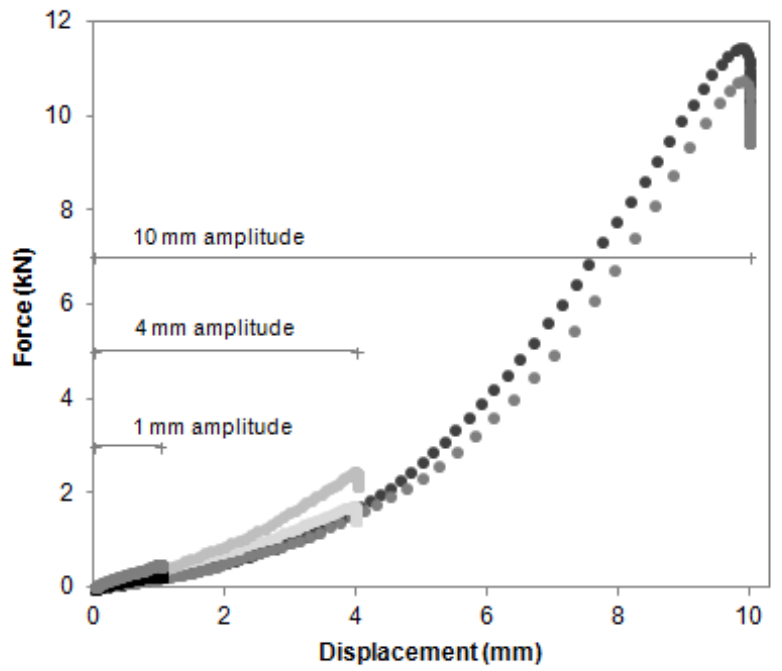

Figure 11. Force vs. displacement relationship for selected dynamic strain-controlled shear tests of 1 $\mathrm{mm}, 4 \mathrm{~mm}$ and $10 \mathrm{~mm}$ total displacements 


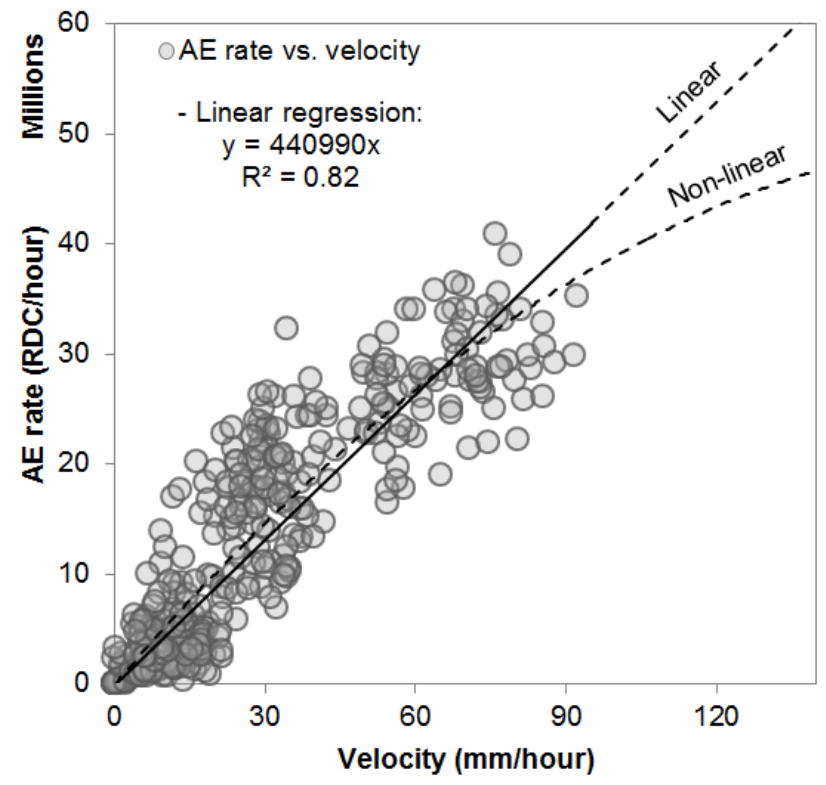

Figure 12. Measured AE rate vs. measured velocity relationship using data from 21 dynamic straincontrolled shear tests

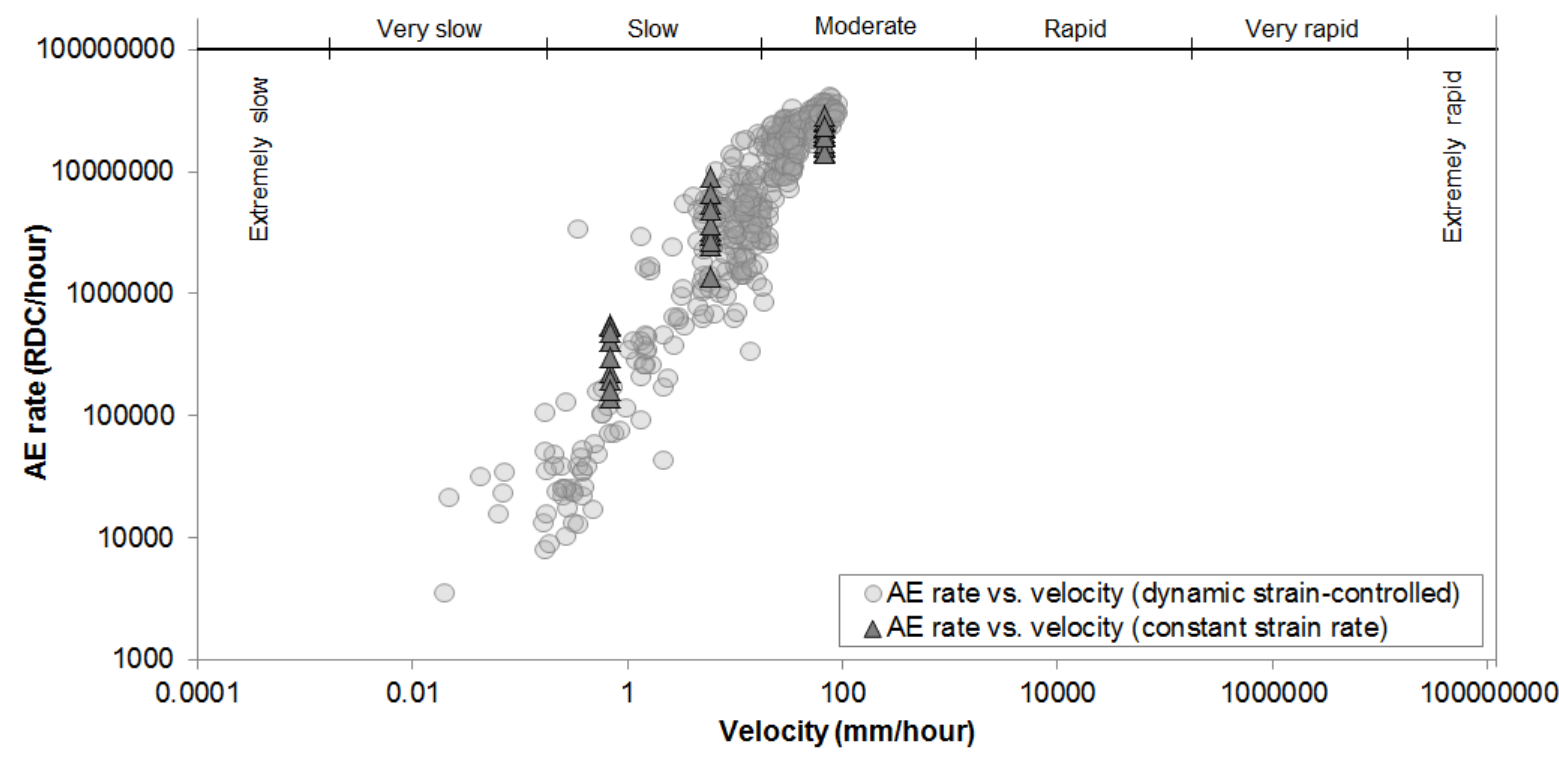

Figure 13. Measured AE rate vs. measured velocity relationship using data from 21 dynamic straincontrolled shear tests and 40 constant strain rate compression tests, the landslide velocity scale after Anderson \& Holcombe (2013, p92) is superimposed 


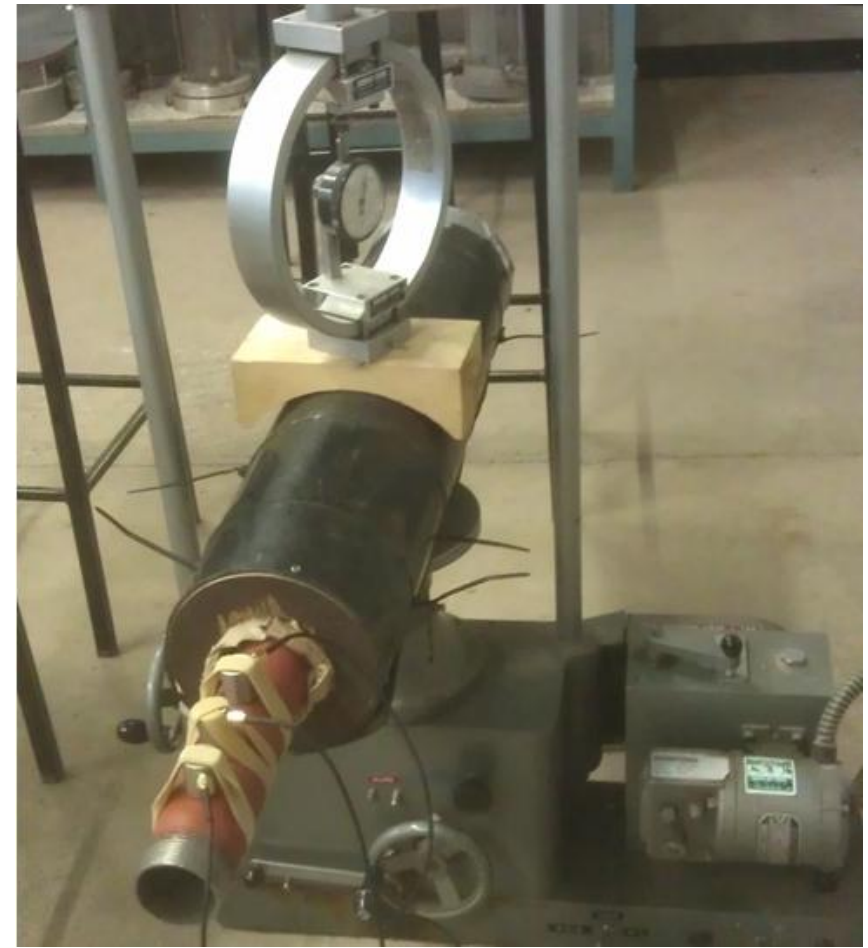

Figure 14. Photograph of the active waveguide model installed in the Dixon \& Spriggs (2007) compression apparatus

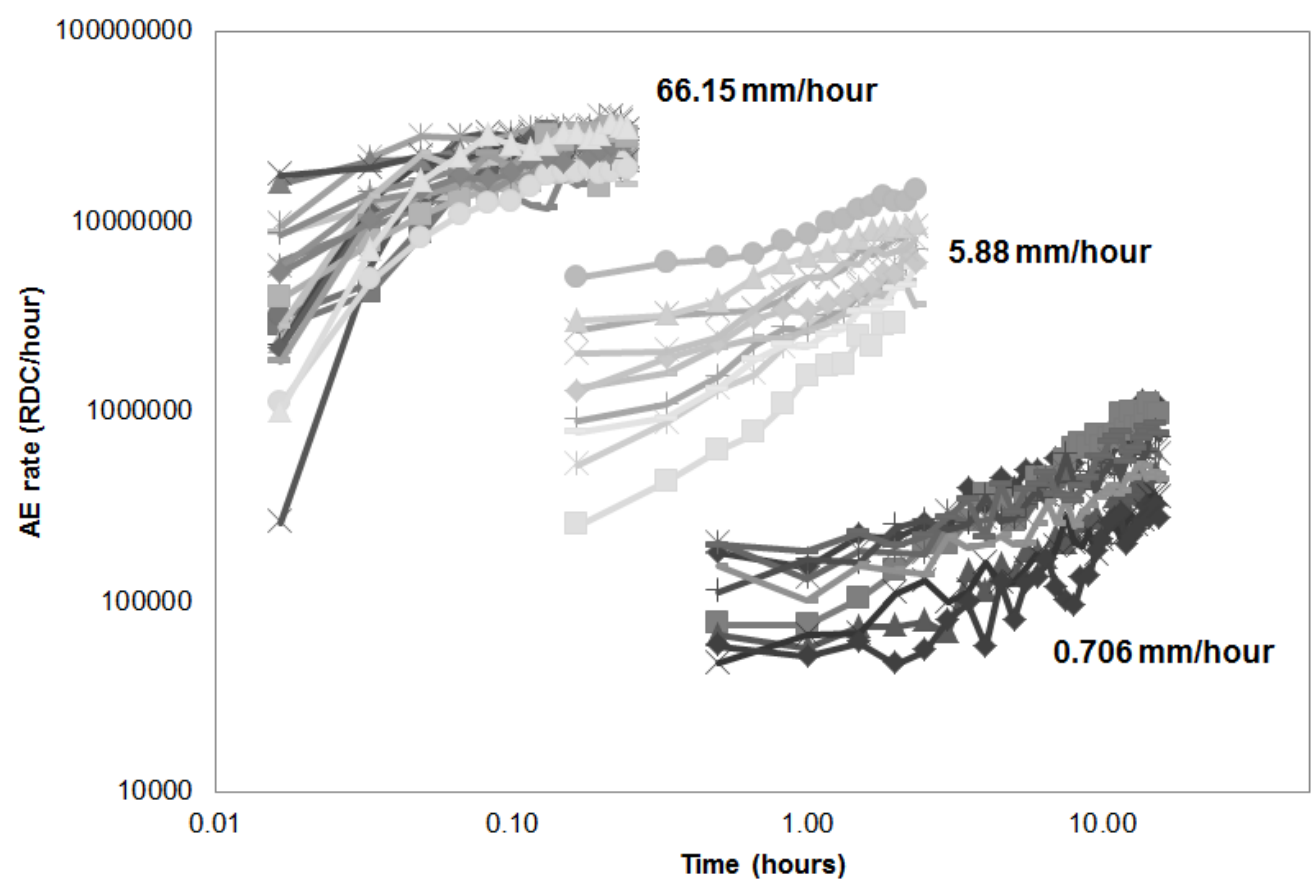

Figure 15. Results from 40 constant strain rate compression tests; AE rate vs. time 


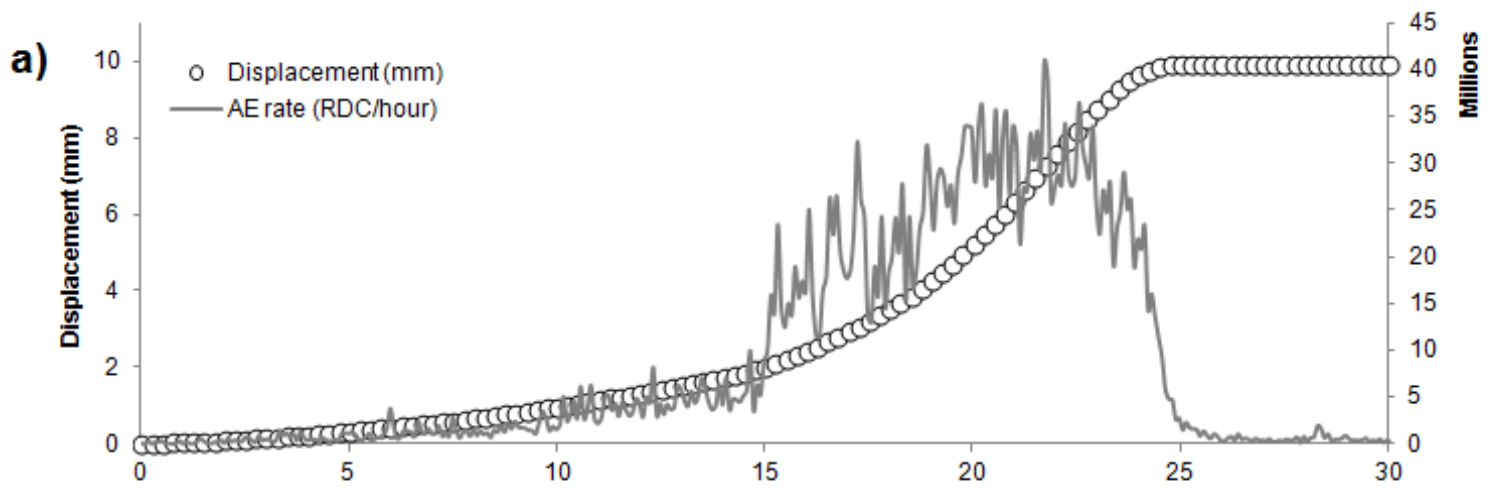

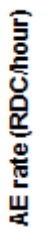
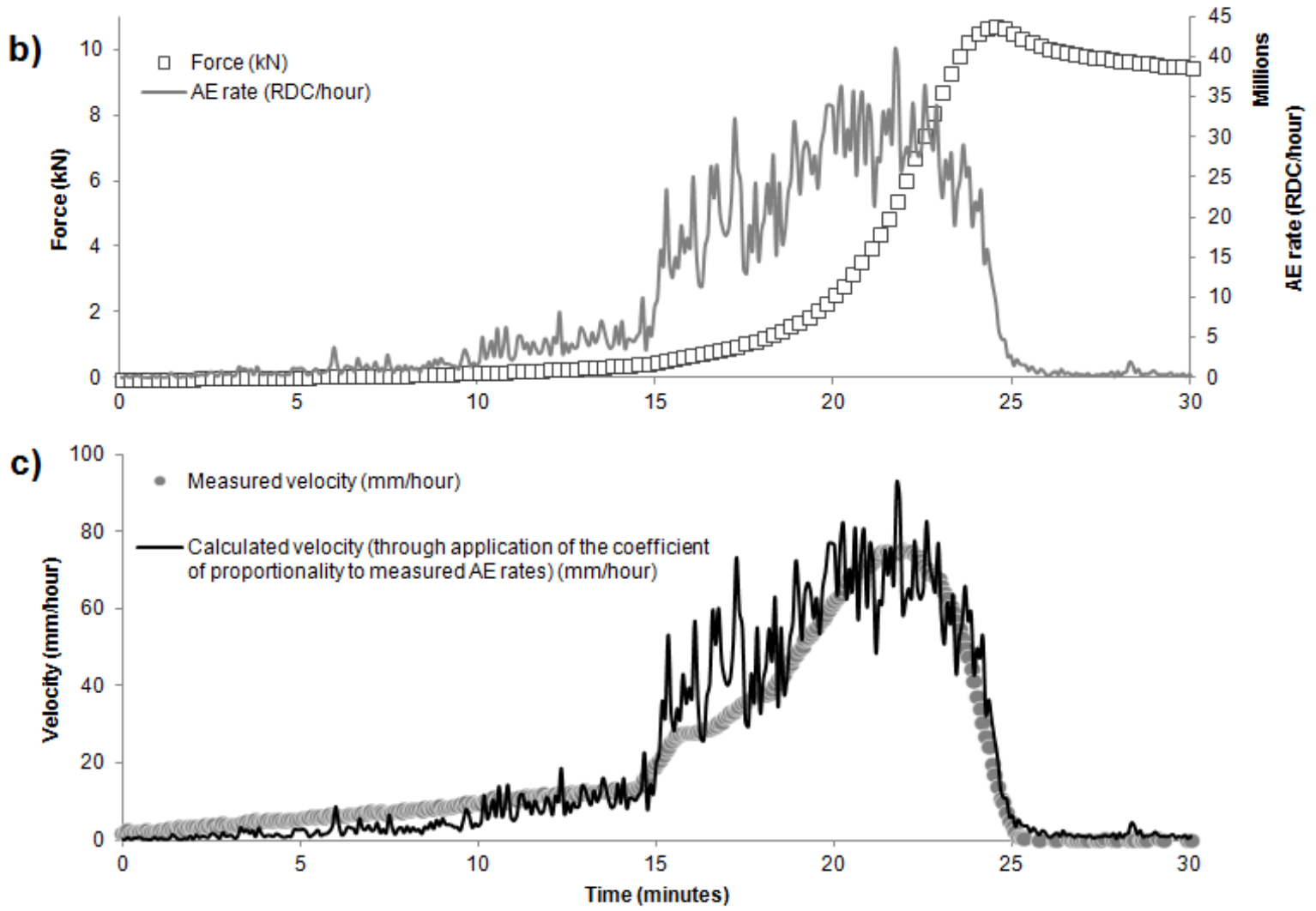

Figure 16. Time series from a dynamic strain-controlled failure simulation; a) displacement- and AE rate-time, b) force- and $\mathrm{AE}$ rate-time, and c) measured velocity- and calculated velocity (i.e. derived from $\mathrm{AE}$ rate 5 second interval values)-time 

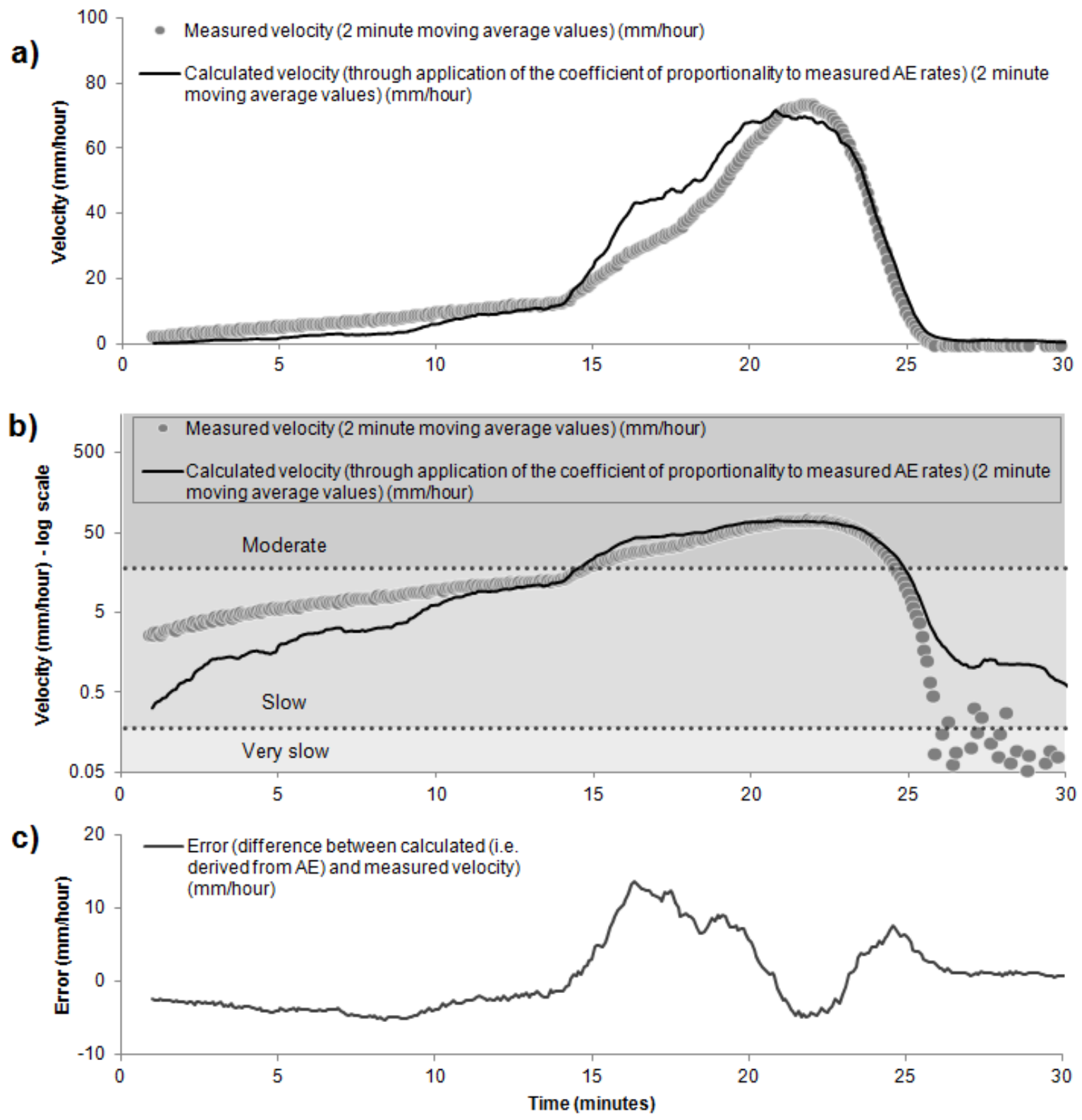

Figure 17. Measured and calculated (i.e. derived from AE rate data through application of the coefficient of proportionality) velocity-time behaviour ( 2 minute moving average values) during a landslide failure simulation using the dynamic strain-controlled shear test apparatus; a) linear velocity scale, b) log velocity scale showing 'very slow', 'slow' and 'moderate' velocity classifications, and c) error (difference between calculated (i.e. derived from AE) and measured velocities (using 2 minute moving average values) 


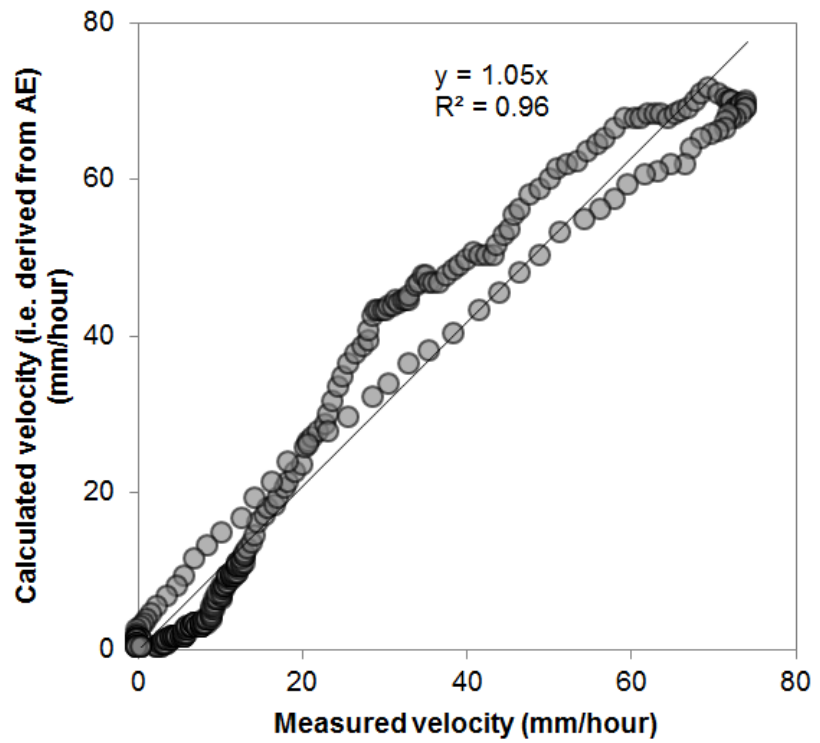

Figure 18. Calculated velocity (i.e. derived from AE rate data through application of the coefficient of proportionality) vs. measured velocity throughout the slope failure simulation 